\title{
PENGARUH KOMITMEN KERJA DAN QUALITY OF WORK LIFE (QWL) TERHADAP KEPUASAN KERJA DAN DAMPAKNYA TERHADAP KINERJA KARYAWAN PT. INDOFOOD CBP SUKSES MAKMUR CABANG JAMBI
}

\author{
Fathiyah, Ahmad Firdaus, Alex Kurnia Putra \\ Fakultas Ekonomi -Magister Manajemen-Universitas Batanghari Jambi
}

\begin{abstract}
The purposes this research are to examine the influence of work commitment, Quality of Work Life ( $Q W L)$, job satisfaction and employee performance. The influences of work commitment, Quality of Work Life (QWL), job satisfaction and employee performance tested both directly and indirectly by taking a sample of 80 employees. To test the variables used in research conducted a survey of employees at PT. Indofood CBP Sukses Makmur Jambi Branch. Framework of theory and data analysis is done by using Path Analysis. The results of this research indicate that the work commitment, Quality of Work Life (QWL) and job satisfaction influential support directly and indirectly to the performance of employees is positive and significant impact. The analysis tool in this research using descriptive methods and verification. Where a descriptive study using a range of scales, while in verification using path analysis. Based on the results are reflection that work commitment, Quality of Work Life $(Q W L)$, job satisfaction is an important issue to improve performance of employees. Results of the study revealed that the results related to the employee's performance is important to manage the company. Optimizing the quality of work through constant work evaluation on appropriate working standards are set, action inconsistent to individuals may lead to other negative consequences in the company, such a low performance, resistance to the organization and may indicate the behavior of disobedience the employees.
\end{abstract}

Keywords: work commitment, QWL, job satisfaction and performance

\section{PENDAHULUAN}

Salah satu masalah pokok dalam manajemen sumber daya manusia adalah bagaimana mencari cara yang terbaik untuk mencapai kepuasan karyawan. Kepuasan kerja karyawan merupakan salah satu aspek penting yang perlu diperhatikan dalam usaha peningkatan kualitas sumber daya manusia suatu perusahaan, apabila kepuasan kerja karyawan terpenuhi, mereka akan cenderung memiliki motivasi untuk bekerja, sebaliknya ketidakpuasan akan mengakibatkan tingginya tingkat keluar masuk karyawan, ketidakhadiran, pemogokan, dan tindakan-tindakan negatif lainnya yang dapat merugikan perusahaan.

Quality of Work Life merupakan masalah utama yang patut mendapat perhatian organisasi (Lewis dkk, 2001). Adanya kualitas kehidupan kerja (Quality of Work Life) juga menumbuhkan keinginan para karyawan untuk tetap tinggal dan bertahan di dalam organisasi. Hal itu juga dapat dinilai bahwa karyawan menunjukkan rasa puasnya terhadap perlakuan perusahaan terhadap dirinya. Kepuasan dapat dipandang sebagai pernyataan positif hasil dari penilaian para karyawan terhadap apa yang telah dilakukan oleh perusahaan/organisasi kepada para karyawannya. Kepuasan karyawan akan dapat menumbuhkan komitmen dan loyalitas karyawan. 
Setiap individu menginginkan kinerja yang memuaskan. Nilai yang sangat memuaskan tersebut akan menuntun mereka menapak karir lebih baik di masa yang akan datang. Namun sebaliknya apabila hasil penilaian tersebut mengecewakan mereka maka berarti sangat kecil kemungkinan peluang mendapat promosi karir di masa yang akan datang. Dari beberapa variabel yang dapat mempengaruhi kinerja maka dalam kajian ini berupaya mengkaji variabel komitmen kerja, Quality Of Work Life (QWL) dan kepuasan kerja. Komitmen kerja merupakan dasar yang dapat mendorong seseorang untuk bekerja atau melakukan sesuatu guna mencapai tujuan yang telah digariskan oleh organisasi, yaitu dengan menjaga konsistensi dan keteguhan hati dalam bekerja, sementara QWL merupakan gambaran dari sikap hidup yang berkualitas yang selalu memandang perilaku dari sudut yang positif, sementara kepuasan kerja sendiri merupakan gambaran dari sikap atas pandangan terhadap hasil pekerjaan yang telah dilakukan oleh seseorang.

Penelitian menunjukkan adanya hubungan positif antara praktek kualitas kehidupan kerja dengan komitmen dan kinerja karyawan (Aripin, 2012). Penelitian yang dilakukan oleh Wyatt dan Wah (2001) terhadap pekerja di Singapura menyebutkan bahwa pekerja ingin diperlakukan sebagai individu yang dihargai di tempat kerja. Kinerja yang bagus akan dihasilkan pekerja jika mereka dihargai dan diperlakukan seperti layaknya manusia dewasa. Hasibuan (2003), menyatakan bahwa tolak ukur yang mutlak dalam mengukur tingkat kepuasan tidak ada, oleh karena itu diperlukan suatu cara dalam mengukur tingkat kepuasan karyawan suatu perusahaan atau organisasi. Salah satu cara dalam mengukur tingkat kepuasan karyawan adalah dengan mengetahui perasaan karyawan terhadap aspek-aspek yang berpengaruh terhadap kualitas kehidupan kerjanya atau quality of work life. Kualitas kehidupan kerja merupakan upaya untuk mencapai kinerja yang unggul, produktivitas yang tinggi dan upaya untuk mencapai kepuasan diri dan lingkungan kerja yang optimal (Arifin, 2009).

Sebagai perusahaan nasional Indonesia yang memiliki misi sebagai penyedia solusi kebutuhan pangan, PT. Indofood CBP Tbk, berkontribusi memberikan produk makanan olahan bermutu yang aman, hiegienes serta halal, yang tersebar diseluruh penjuru Nusantara dan menembus pasar mancanegara. PT. Indofood CBP Sukses Makmur divisi Noodle yang mempunyai berbagai cabang dalam hal ini di Jambi khususnya harus senantiasa meningkatkan kualitasnya agar dapat unggul dalam bersaing dengan perusahaan perusahaan kompetitornya. Produk yang berkualitas hanya dapat diperoleh dari sumber daya manusia yang memiliki kualitas yang tinggi. Seperti halnya perusahaan lainnya, PT. Indofood CBP Sukses Makmur cabang Jambi berupaya untuk meningkatkan kinerja organisasi dan kinerja individu.

Berdasarkan ulasan kinerja yang dicapai dalam Annual Report 2014 Indofood CBP makmur divisi me instan menghadapi tekanan biaya selama semester pertama tahun 2014 akibat melemahnya nilai tukar rupiah, yang berdampak volume penjualan sedikit menurun menjadi 12,59 miliar bungkus dari 12,65 miliar bungkus di tahun 2013. Inovasi tetap menjadi fokus utama Divisi Mi Instan. Peluncuran berbagai produk baru guna memenuhi perubahan permintaan pasar maupun menawarkan rasa-rasa baru yang mengundang selera konsumen, terus dilakukan. Kegiatan pemasaran terus dilaksanakan guna memperkuat brand equity dan mendukung peluncuran berbagai produk baru dan pengembangan hasil olahan dan produksi secara intensif. Dalam hal hasil olahan, produksi yang dihasilkan dan upaya pemasaran menuntut konsentrasi dan ketenangan dalam 
bekerja. Hal ini dapat terlaksana apabila terdapat suatu kondisi iklim kerja atau Quality of Work Life yang baik dan akan berpengaruh terhadap komitmen kerja karyawan dan akan memberi dampak kepada kepuasan kerja yang pada akhirnya akan mempengaruhi kinerja karyawan secara keseluruhan.

\section{METODE PENELITIAN}

Metode penelitian yang digunakan dalam penelitian ini adalah penelitian deskriptif dengan pendekatan kuantitatif dan verifikatif. Pendekatan kuantitatif digunakan karena peneliti bermaksud mengumpulkan dan menganalisa bukti empiris (data) dan melakukan pengujian data secara statistik serta dilakukan secara sistematis agar dapat memahami fenomena sosial yang tengah diteliti, (Nazir, 2003). Khusus tentang pengaruh komitmen kerja dan QWL terhadap kepuasan kerja serta implikasinya terhadap kinerja karyawan pada PT. Indofood CBP Sukses Makmur Cabang Jambi, sementara penelitian verfikatif bermaksud untuk menerapkan analisis yang lebih rinci dan mendalam. fokus penelitian ditetapkan terbatas pada domain tertentu. Penggunaan metode ini berdasar pada tujuan dan pokok penelitian, yaitu mendeskripsikan dan menganalisis secara menyeluruh dan utuh tentang Pengaruh Komitmen kerja, QWL dan Kepuasan kerja dengan Kinerja karyawan pada PT. Indofood CBP Sukses Makmur Cabang Jambi.

\section{HASIL DAN PEMBAHASAN}

\section{Validitas}

Pengujian terhadap validitas instrumen yang digunakan dalam penelitian ini dimaksudkan untuk mengukur sah tidaknya suatu kuesioner.

Tabel 1. Hasil Perhitungan Uji Validitas Variabel Komitmen Kerja Karyawan

\begin{tabular}{|c|c|c|c|c|}
\hline \multirow{2}{*}{$\begin{array}{c}\text { Butir } \\
\text { Pertanyaan }\end{array}$} & \multicolumn{4}{|c|}{ Perbandingan $r$ hitung dengan $r$ tabel } \\
\hline & r hitung & $\mathrm{r}$ tabel & Keterangan & Validitas \\
\hline Komitmen_1 & 0,484 & & $\mathrm{r}$ hit $>\mathrm{r}$ tab & Valid \\
\hline Komitmen_2 & 0,314 & & $\mathrm{r}$ hit $>\mathrm{r}$ tab & Valid \\
\hline Komitmen_3 & 0,353 & & $\mathrm{r}$ hit $>\mathrm{r}$ tab & Valid \\
\hline Komitmen_4 & 0,368 & & $\mathrm{r}$ hit $>\mathrm{r}$ tab & Valid \\
\hline Komitmen_5 & 0,436 & 0.235 & $\mathrm{r}$ hit $>\mathrm{r}$ tab & Valid \\
\hline Komitmen_6 & 0,494 & & $\mathrm{r}$ hit $>\mathrm{r}$ tab & Valid \\
\hline Komitmen_7 & 0,353 & & $\mathrm{r}$ hit $>\mathrm{r}$ tab & Valid \\
\hline Komitmen_8 & 0,349 & & $\mathrm{r}$ hit $>\mathrm{r}$ tab & Valid \\
\hline Komitmen_9 & 0,301 & & $\mathrm{r}$ hit $>\mathrm{r}$ tab & Valid \\
\hline Komitmen_10 & 0,519 & & $\mathrm{r}$ hit $>\mathrm{r}$ tab & Valid \\
\hline
\end{tabular}

Sumber : Hasil Perhitungan (lampiran 6) 
Tabel 2. Hasil Perhitungan Uji Validitas Variabel QWL

\begin{tabular}{|c|c|c|c|c|}
\hline \multirow{2}{*}{$\begin{array}{c}\text { Butir } \\
\text { Pertanyaan }\end{array}$} & \multicolumn{4}{|c|}{ Perbandingan $r$ hitung dengan $r$ tabel } \\
\hline & $\mathrm{r}$ hit & r tabel & Keterangan & Validitas \\
\hline QWL_1 & 0,408 & & $\mathrm{r}$ hit $>\mathrm{r}$ tab & Valid \\
\hline QWL_2 & 0,358 & & $\mathrm{r}$ hit $>\mathrm{r}$ tab & Valid \\
\hline QWL_3 & 0,320 & & $\mathrm{r}$ hit $>\mathrm{r}$ tab & Valid \\
\hline QWL_4 & 0,467 & & $\mathrm{r}$ hit $>\mathrm{r}$ tab & Valid \\
\hline QWL_5 & 0,380 & & $\mathrm{r}$ hit $>\mathrm{r}$ tab & Valid \\
\hline QWL_6 & 0,377 & & $\mathrm{r}$ hit $>\mathrm{r}$ tab & Valid \\
\hline QWL_7 & 0,448 & 0.235 & $\mathrm{r}$ hit $>\mathrm{r}$ tab & Valid \\
\hline QWL_8 & 0,431 & & $\mathrm{r}$ hit $>\mathrm{r}$ tab & Valid \\
\hline QWL_9 & 0,463 & & $\mathrm{r}$ hit $>\mathrm{r}$ tab & Valid \\
\hline QWL_10 & 0,450 & & $\mathrm{r}$ hit $>\mathrm{r}$ tab & Valid \\
\hline QWL_11 & 0,575 & & $\mathrm{r}$ hit $>\mathrm{r}$ tab & Valid \\
\hline QWL_12 & 0,470 & & $\mathrm{r}$ hit $>\mathrm{r}$ tab & Valid \\
\hline QWL_13 & 0,437 & & $r$ hit $>r$ tab & Valid \\
\hline QWL_14 & 0,511 & & $\mathrm{r}$ hit $>\mathrm{r}$ tab & Valid \\
\hline
\end{tabular}

Sumber : Hasil Perhitungan (lampiran 6)

Tabel 3. Hasil Perhitungan Uji Validitas Variabel Kepuasan Kerja

\begin{tabular}{|c|c|c|c|c|}
\hline Butir & \multicolumn{4}{|c|}{ Perbandingan $r$ hitung dengan $r$ tabel } \\
\hline Pertanyaan & r hitung & r tabel & Keterangan & Validitas \\
\hline Kepker_1 & 0,365 & & $\mathrm{r}$ hit $>\mathrm{r}$ tab & Valid \\
\hline Kepker_2 & 0,442 & & $\mathrm{r}$ hit $>\mathrm{r}$ tab & Valid \\
\hline Kepker_3 & 0,594 & & r hit $>$ r tab & Valid \\
\hline Kepker_4 & 0,480 & & $\mathrm{r}$ hit $>\mathrm{r}$ tab & Valid \\
\hline Kepker_5 & 0,410 & 0.235 & r hit $>$ r tab & Valid \\
\hline Kepker_6 & 0,352 & & r hit $>$ r tab & Valid \\
\hline Kepker_7 & 0,395 & & r hit $>$ r tab & Valid \\
\hline Kepker_8 & 0,455 & & r hit $>$ r tab & Valid \\
\hline Kepker_9 & 0,531 & & $\mathrm{r}$ hit $>\mathrm{r}$ tab & Valid \\
\hline Kepker_10 & 0,462 & & r hit $>$ r tab & Valid \\
\hline
\end{tabular}

Sumber : Hasil Perhitungan (lampiran 6)

Tabel 4. Hasil Perhitungan Uji Validitas Variabel Kinerja

\begin{tabular}{|c|c|c|c|c|}
\hline \multirow{2}{*}{$\begin{array}{c}\text { Butir } \\
\text { Pertanyaan }\end{array}$} & \multicolumn{4}{|c|}{ Perbandingan $r$ hitung dengan $r$ tabel } \\
\hline & r hitung & r tabel & Keterangan & Validitas \\
\hline Kinerja_1 & 0,445 & & $\mathrm{r}$ hit $>\mathrm{r}$ tab & Valid \\
\hline Kinerja_2 & 0,420 & & $\mathrm{r}$ hit $>\mathrm{r}$ tab & Valid \\
\hline Kinerja_3 & 0,576 & & $\mathrm{r}$ hit $>\mathrm{r}$ tab & Valid \\
\hline Kinerja_4 & 0,432 & 0.235 & $\mathrm{r}$ hit $>\mathrm{r}$ tab & Valid \\
\hline Kinerja_5 & 0,490 & & $\mathrm{r}$ hit $>\mathrm{r}$ tab & Valid \\
\hline Kinerja_6 & 0,438 & & $\mathrm{r}$ hit $>\mathrm{r}$ tab & Valid \\
\hline Kinerja_7 & 0,427 & & $\mathrm{r}$ hit $>\mathrm{r}$ tab & Valid \\
\hline Kinerja_8 & 0,477 & & $\mathrm{r}$ hit $>\mathrm{r}$ tab & Valid \\
\hline
\end{tabular}

Sumber : Hasil Perhitungan (lampiran 6) 
2. Reliabilitas

Tabel 5. One-Sampel Kolmogorov-Smirnov Test

\begin{tabular}{llrrrr}
\hline & & Komitmen & QWL & Kepuasan kerja & Kinerja \\
\hline $\mathrm{N}$ & & 80 & 80 & 80 & 80 \\
Normal Parameters $^{\mathrm{a}}$ & Mean & 32.4875 & 31.1750 & 31.6750 & 27.6250 \\
& Std. Deviation & 2.43910 & 3.29470 & 3.61703 & 3.14371 \\
Most Extreme & Absolute & .158 & .121 & .061 & .103 \\
Differences & Positive & .143 & .121 & .060 & .093 \\
& Negative & -.158 & -.065 & -.061 & -.103 \\
Kolmogorov-Smirnov Z Z & 1.416 & 1.084 & .544 & .918 \\
Asymp. Sig. (2-tailed) & .536 & .191 & .929 & .369 \\
\hline
\end{tabular}

a. Test distribution is Normal.

Berdasarkan tabel diatas nampak bahwa nilai signifikansi untuk masingmasing variabel (lihat pada baris Asym. Sig. (2-tailed)) lebih besar dari nilai $\alpha$ $=5 \%$. Ketentuan yang berlaku adalah, jika Nilai signifikansi dalam tabel Kolmogorov Smirnov lebih besar dari nilai $\alpha$ yang dalam hal ini ditetapkan sebesar 5\%, maka kesemua variabel yang diteliti dikatakan berdistribusi Normal.

\section{Pengaruh Komitmen Kerja dan QWL Secara bersama-sama terhadap Kinerja}

Untuk menguji pengaruh komitmen kerja $\left(\mathrm{X}_{1}\right)$ dan QWL $\left(\mathrm{X}_{2}\right)$ terhadap kinerja karyawan $(\mathrm{Y})$ digunakan analisis regresi linier berganda, dimana kedua variabel independen (komitmen kerja dan QWL) akan diregresikan secara bersama-sama terhadap kinerja karyawan, adapun persamaan struktur yang ditampilkan adalah sebagai berikut :

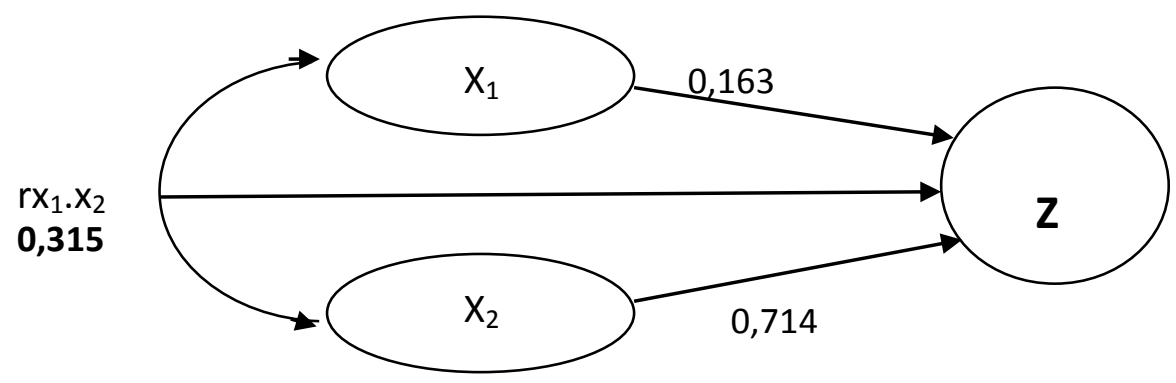

\section{Gambar 1. Pengaruh Komitmen Kerja dan QWL Secara bersama-sama terhadap Kinerja}

Untuk menjawab tujuan kelima mengenai hubungan antara komitmen kerja dan QWL secara bersama-sama terhadap kinerja maka dapat dilihat pada hasil perhitungan sebagai berikut :

a. Pengaruh Langsung $X 1$ dan $X 2$ terhadap $Z$

$$
\begin{aligned}
\mathrm{X}_{1} \text { dan } \mathrm{X}_{2} \rightarrow \mathrm{Z} & =\mathrm{X} 1 \& \mathrm{X} 2 \Omega \mathrm{Z} \\
& =\left(\mathrm{Pzx}_{1} \cdot \mathrm{Pzx}_{1}\right)+\left(\mathrm{Pzx}_{2} \cdot \mathrm{Pzx}_{2}\right) \\
& =(0,163 \times 0,163)+(0,714 \times 0,714) \\
& =0.0265+0.5097 \\
& =0.5362 \text { atau sebesar } 53.62 \%
\end{aligned}
$$


b. Pengaruh tidak langsung $X 1 \& X 2$ terhadap $Z$

$\mathrm{X}_{1}$ dan $\mathrm{X}_{2} \rightarrow \mathrm{Z}=\left(\mathrm{Pzx}_{1} \cdot \mathrm{rx}_{1} \mathrm{X}_{2} \cdot \mathrm{Pzx}_{1}\right)+\left(\mathrm{Pzx}_{2} \cdot \mathrm{rx}_{1} \mathrm{X}_{2} \cdot \mathrm{Pzx}_{2}\right)$

$=0.00836+0.1605$

$=0.1688$ atau sebesar $16.88 \%$

c. Total Pengaruh langsung dan tidak langsung

$$
=53.62+16.88=70.5 \%
$$

Adapun gambaran angka-angka struktur hubungan $\mathrm{Z}=\mathrm{Pzx}_{1} \cdot \mathrm{x}_{1}+$ $\mathrm{Pzx}_{2} . \mathrm{X}_{2}$ tergambar pada tabel berikut:

Tabel 6. Nilai-Nilai Koefisien Pengaruh Komitmen Kerja dan QWL Terhadap Kinerja karyawan

\begin{tabular}{|c|c|c|c|c|c|c|}
\hline \multirow{2}{*}{\multicolumn{2}{|c|}{ Model }} & \multicolumn{2}{|c|}{$\begin{array}{l}\text { Unstandardized } \\
\text { Coefficients }\end{array}$} & \multirow{2}{*}{$\begin{array}{c}\text { Standardized } \\
\text { Coefficients } \\
\text { Beta }\end{array}$} & \multirow[b]{2}{*}{$\mathrm{t}$} & \multirow[b]{2}{*}{ Sig. } \\
\hline & & B & Std. Error & & & \\
\hline 1 & $\begin{array}{l}\text { (Constant } \\
\text { ) }\end{array}$ & .380 & .328 & & 1.159 & .251 \\
\hline & $\mathrm{X} 1$ & .296 & .090 & .163 & 3.276 & .002 \\
\hline & $\mathrm{X} 2$ & .631 & .091 & .714 & 6.967 & .000 \\
\hline
\end{tabular}

a. Dependent Variable: $\mathrm{Z}$

Berdasarkan persamaan struktur regresi di atas dapat diterjemahkan bahwa pengaruh komitmen kerja dan QWL terhadap kepuasan kerja karyawan Indofood CBP Sukses Makmur Cabang Jambi adalah sebesar 0.5362 atau sebesar $53.62 \%$. Namun demikian pengaruh tidak langsung komitmen kerja dan QWL terhadap kinerja yaitu sebesar $16.88 \%$, dengan demikian maka pengaruh total komitmen kerja dan QWl terhadap kinerja adalah sebesar $70.5 \%$.

Selanjutnya untuk melihat keberartian (signifikansi) apakah secara bersama-sama komitmen kerja dan QWL memiliki hubungan hubungan yang linearitas dengan kinerja maka dilakukan analisis uji F. Berdasarkan lampiran 10 diperoleh nilai $\mathrm{F}$ hitung sebesar 62.554 sementara dengan tingkat keyakinan sebesar 95\% DF $=\mathrm{n}-\mathrm{k}$ 80-2 diperoleh nilai $\mathrm{F}$ tabel sebesar 3.15 .

Dengan demikian maka nilai $\mathrm{F}$ hitung (62.554) lebih besar dari nilai $\mathrm{F}$ tabel (3.15) dengan demikian maka terdapat pengaruh linear yang sangat kuat antara variabel komitmen kerja karyawan dan QWL terhadap kinerja karyawan.

\section{Pengaruh Komitmen Kerja secara parsial terhadap Kinerja}

Berdasarkan hasil pengujian sebagaimana tergambar pada lampiran 10 untuk menjawab tujuan ke enam maka diperoleh hasil pengujian besarnya pengaruh langsung dan tidak langsung $\mathrm{X} 1$ terhadap $\mathrm{Z}$ sebagai berikut :

a. Pengaruh langsung $\mathrm{X} 1$ terhadap $\mathrm{Z}$

$$
\begin{aligned}
\mathrm{X}_{1} \rightarrow \mathrm{Z} & =\mathrm{X} 1 \Omega \mathrm{Z} \\
& =\left(\mathrm{Pzx}_{1}\right) \cdot\left(\mathrm{Pzx}_{1}\right) \\
& =(0.613)(0.613) \\
& =0.0265 \text { atau sebesar } 2.65 \%
\end{aligned}
$$

b. Pengaruh tidak langsung X1 terhadap Z melalui X2

$\mathrm{X}_{1} \rightarrow \mathrm{Z}$ melalui $\mathrm{X}_{2}=\mathrm{X} 1 \Omega \mathrm{X} 2 \rightarrow \mathrm{Z}$

$$
\begin{aligned}
& =\left(\mathrm{PzX}_{1}\right) \cdot\left(\mathrm{rx}_{1} \mathrm{X}_{2}\right) \cdot\left(\mathrm{PzX}_{2}\right) \\
& =(0,163)(0,315)(0,714)
\end{aligned}
$$




$$
=0.0366 \text { atau sebesar } 3.66 \%
$$

c. Total pengaruh langsung dan tidak langsung

$$
=2.65 \%+3.66 \%=6.31 \%
$$

Berdasarkan struktur persamaan regresi dan hasil perhitungan di atas maka dapat disusun pengaruh langsung pengaruh komitmen kerja terhadap kinerja dan pengaruh tidak langsung komitmen kerja melalui kepuasan kerja terhadap kinerja karyawan sebagai berikut :

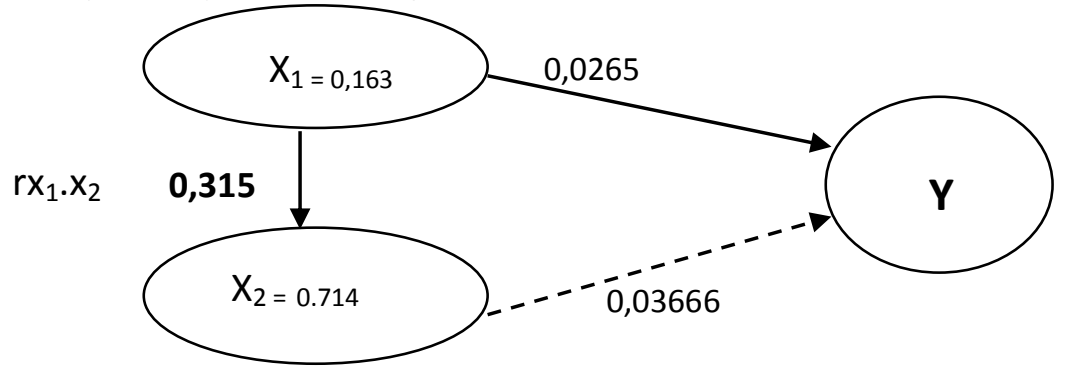

\section{Gambar 2. Pengaruh Komitmen kerja terhadap Kinerja}

Berdasarkan persamaan struktur regresi di atas dapat diterjemahkan bahwa pengaruh komitmen kerja terhadap kinerja karyawan Indofood CBP Sukses Makmur Cabang Jambi adalah sebesar 0,0265 atau sebesar 2,6 \%, namun demikian pengaruh tidak langsung komitmen kerja melalui kepuasan kerja terhadap kinerja karyawan lebih besar yaitu sebesar 0,03666 atau sebesar 3,66\%, dengan pengaruh total sebesar 6,31\%.

Dengan nilai t hitung sebesar 3,276 dan nilai t tabel pada tingkat keyakinan sebesar $96 \%$ atau 0,05 dan nilai $\mathrm{df}=\mathrm{n}-\mathrm{k}$ atau 80-3 $=77$ maka diperoleh nilai $t$ tabel sebesar 1,6660 . Hal ini berarti nilai t hitung $(3,276)$ lebih besar dari nilai $t$ tabel $(1,6660)$. Sesuai dengan kaidah pengambilan keputusan maka berarti bahwa komitmen kerja secara langsung berpengaruh secara signifikan terhadap kinerja karyawan.

Hasil penelitian ini sejalan dengan penelitian yang dilakukan oleh McNeese-Smith (1996) menunjukkan bahwa komitmen organisasi berhubungan signifikan positif yang ditunjukkan dengan nilai Pearson (r) sebesar 0,31 (signifikan pada level 0,001) terhadap kinerja karyawan produksi.

\section{Pengaruh QWL secara parsial terhadap Kinerja}

Untuk menjawab tujuan ketujuh yaitu besarnya pengaruh langsung dan tidak langsung dari persamaan struktural pengaruh QWL terhadap kinerja adalah sebagai berikut :

a. Pengaruh langsung X2 terhadap Z

$$
\begin{aligned}
\mathrm{X}_{2} \rightarrow \mathrm{Z} & =\mathrm{X} 2 \Omega \mathrm{Z} \\
& =\left(\mathrm{Pzx}_{2}\right) \cdot\left(\mathrm{Pzx}_{2}\right) \\
& =(0,714)(0,714) \\
& =0.5097 \text { atau sebesar } 50.97 \%
\end{aligned}
$$

b. Pengaruh tidak langsung $X 2$ terhadap $Z$ melalui $X 1$

$\mathrm{X}_{2} \rightarrow \mathrm{Z}$ melalui $\mathrm{X}_{1}=\mathrm{X} 2 \Omega \mathrm{X} 1 \rightarrow \mathrm{Z}$

$$
\begin{aligned}
& =\left(\mathrm{Pzx}_{2}\right) \cdot\left(\mathrm{rx}_{1} \mathrm{x}_{2}\right) \cdot\left(\mathrm{Pzx}_{1}\right) \\
& =(0,714) \cdot(0,315) \cdot(0,163) \\
& =0.0366 \text { atau sebesar } 3 \cdot 66 \%
\end{aligned}
$$

c. Total pengaruh langsung dan tidak langsung

$$
=50.97 \%+3.66 \%=54.63 \%
$$


Berdasarkan hasil perhiyungan struktur persamaan regresi di atas maka dapat disusun pengaruh langsung pengaruh QWL terhadap kinerja dan pengaruh tidak langsung QWL melalui kepuasan kerja terhadap kinerja karyawan sebagai berikut :

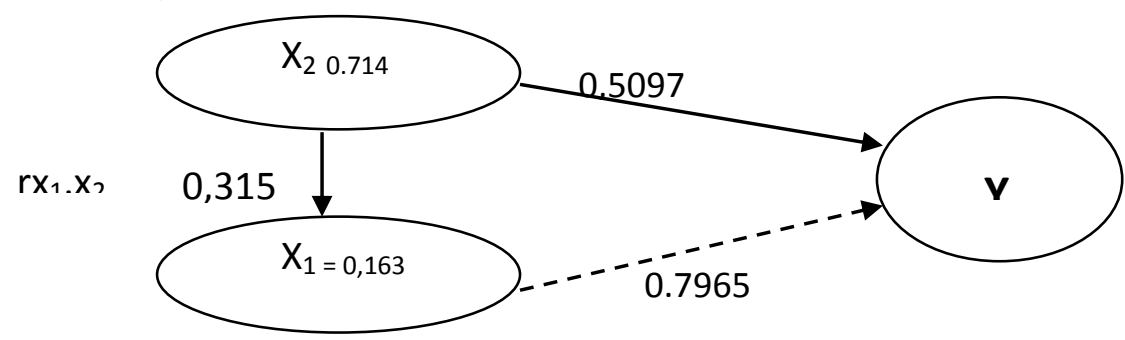

\section{Gambar 3. Pengaruh QWL terhadap Kinerja}

Berdasarkan persamaan struktur regresi di atas dapat diterjemahkan bahwa pengaruh QWL terhadap kinerja karyawan Indofood CBP Sukses Makmur Cabang Jambi adalah sebesar 0,5097 atau sebesar 50,97 \%, namun demikian pengaruh tidak langsung QWL melalui kepuasan kerja terhadap kinerja adalah sebesar 3,66 \%, sehingga pengaruh total QWL terhadap kinerja melalui komitmen kerja adalah sebesar $54,63 \%$

Dengan nilai t hitung sebesar 6,967 dan nilai t tabel pada tingkat keyakinan sebesar $96 \%$ atau 0,05 dan nilai $\mathrm{df}=\mathrm{n}-\mathrm{k}$ atau $80-3=77$ maka diperoleh nilai $t$ tabel sebesar 1,6660. Hal ini berarti nilai t hitung $(6,967)>$ nilai $t$ tabel $(1,6660)$. Sesuai dengan kaidah pengambilan keputusan maka berarti bahwa QWL secara langsung berpengaruh secara signifikan terhadap kinerja karyawan Indofood CBP Sukses Makmur Cabang Jambi.

Hasil penelitian ini mendukung temuan penelitian May dan Lau (1999) juga Emulti Kathawala (1997) yang menyatakan bahwa terdapat hubungan yang positif antara QWL yang efektif dengan kinerja.

6. Pengaruh Komitmen Kerja dan QWL Secara bersama-sama melalui Kepuasan kerja terhadap Kinerja

Untuk menjawab tujuan kedelapan yaitu pengaruh komitmen kerja $\left(\mathrm{X}_{1}\right)$ dan QWL $\left(\mathrm{X}_{2}\right)$ terhadap kinerja karyawan $(\mathrm{Z})$ secara bersama-sama dengan kepuasan kerja digunakan analisis regresi linier berganda, adapun persamaan struktur yang ditampilkan adalah sebagai berikut :

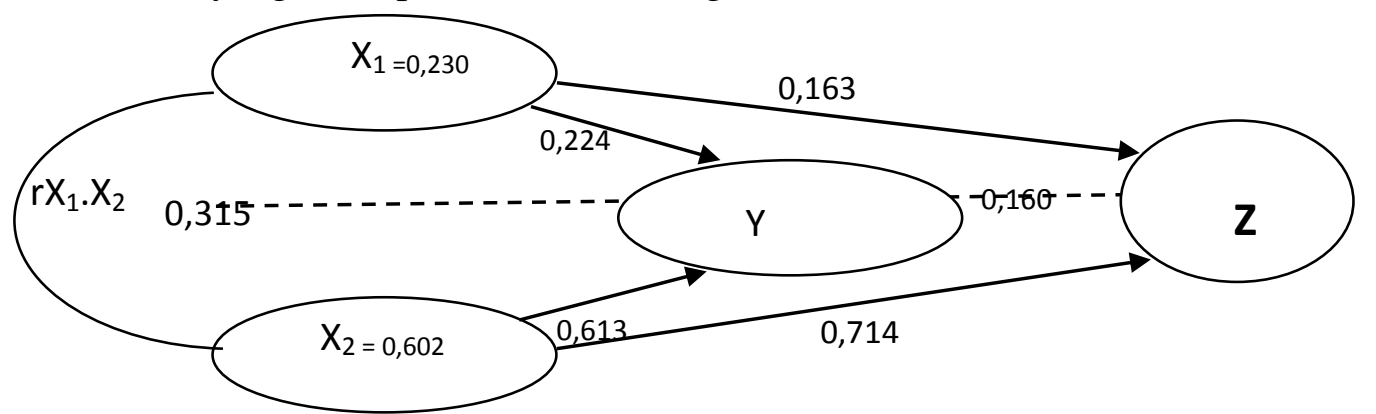

\section{Gambar 4. Pengaruh Komitmen kerja,QWL dan Kepuasan Kerja terhadap Kinerja}

Besarnya pengaruh secara bersama sama antara X1\&X2 terhadap Z melalui $\mathrm{Y}$ adalah sebagai berikut: 
a. Pengaruh langsung dari $\mathrm{X} 1 \& \mathrm{X} 2$ terhadap $\mathrm{Z}$ melalui $\mathrm{Y}$

$$
\begin{aligned}
\mathrm{X}_{1} \operatorname{dan} \mathrm{X}_{2 \Omega} \mathrm{Y} \rightarrow \mathrm{Z} & =\left(\mathrm{Pzx}_{1}\right) \cdot\left(\mathrm{Pyx}_{1}\right) \cdot(\mathrm{Pzy})+\left(\mathrm{Pzx}_{2}\right) \cdot\left(\mathrm{Pyx}_{2}\right)(\mathrm{Pzy}) \\
& =(0.230) \cdot(0.224) \cdot(0.160)+(0.602)(0.613)(0.160) \\
& =0.00824+0.0590 \\
& =0.067 \text { atau sebesar } 6.72 \%
\end{aligned}
$$

b. Pengaruh tidak langsung X1 \& X2 terhadap Z melalui $\mathrm{Y}$ adalah :

$\mathrm{X} 1$ dan $\mathrm{X} 2 \Omega \mathrm{Y} \rightarrow \mathrm{Z} \quad=\mathrm{X} 1 \Omega \mathrm{X} 2, \mathrm{Y} \rightarrow \mathrm{Z}$

$$
\begin{aligned}
= & \left(\mathrm{Pzx}_{1}\right) \cdot\left(\mathrm{Pyx}_{1}\right) \cdot(\mathrm{r} \mathrm{x} 1 \mathrm{x} 2)\left(\mathrm{Pyx}_{2}\right)(\mathrm{Pzy})+ \\
& (\mathrm{Pzx} 2) \cdot(\mathrm{Pyx} 2)(\mathrm{r} \mathrm{x} 1 \mathrm{x} 2)(\mathrm{Pyx} 1)(\mathrm{Pzy}) \\
= & 0.00159+0.00416 \\
= & 0.00575 \text { atau sebesar } 0.57 \%
\end{aligned}
$$

c. Total pengaruh langsung dan tidak langsung

$$
=6.72 \%+0.57 \%=7.29 \%
$$

Pengaruh langsung komitmen kerja dan QWL terhadap kinerja melalui kepuasan kerja adalah sebesar $6.72 \%$, sementara pengaruh tidak langsung adalah sebesar $0.57 \%$, dengan demikian maka pengaruh total komitmen kerja dan QWL melalui kepuasan kerja adalah sebesar 7.29\%

Selanjutnya untuk melihat keberartian (signifikansi) apakah secara bersama-sama komitmen kerja dan QWL serta kepuasan kerja memiliki hubungan hubungan yang linearitas dengan kinerja maka dilakukan analisis uji F. Berdasarkan lampiran 10 diperoleh nilai $\mathrm{F}$ hitung sebesar 45,301 sementara dengan tingkat keyakinan sebesar 95\% DF $=\mathrm{n}-\mathrm{k}$ 80-3=77 diperoleh nilai $F$ tabel sebesar 3,18. Dengan demikian maka nilai $F$ hitung $(45,301)>$ nilai $\mathrm{F}$ tabel $(3,18)$ dengan demikian maka terdapat pengaruh linear yang sangat kuat antara variabel komitmen kerja dan QWL serta kepuasan kerja terhadap kinerja karyawan.

7. Pengaruh langsung dan tidak langsung komitmen kerja melalui kepuasan kerja terhadap Kinerja

Untuk menjawab tujuan kesembilan mengenai hubungan antara komitmen melalui kepuasan kerja terhadap kinerja. Berdasarkan hasil pengujian sebagaimana tergambar pada lampiran 10 diperoleh hasil pengujian sebagai berikut :

a. Pengaruh langsung $\mathrm{X} 1$ terhadap $\mathrm{Z}$ melalui $\mathrm{Y}$

$$
\begin{aligned}
\mathrm{X}_{1} \Omega \mathrm{Y} \rightarrow \mathrm{Z} & =\left(\mathrm{Pzx}_{1}\right) \cdot\left(\mathrm{Pyx}_{1}\right) \cdot(\mathrm{Pzy}) \\
& =(0,230 \times 0,224 \times 0,160) \\
& =0.00824 \text { atau sebesar } 0.82 \%
\end{aligned}
$$

b. Pengaruh tidak langsung $\mathrm{X} 1$ terhadap $\mathrm{Z}$ melalui $\mathrm{Y}$

$$
\begin{aligned}
\mathrm{X}_{1} \Omega \mathrm{Y} \rightarrow \mathrm{Z} & =\left(\mathrm{Pzx}_{1} \cdot \mathrm{rx}_{1} \mathrm{X}_{2} \cdot \mathrm{Pyx}_{2} . \mathrm{Pzy}\right) \\
& =(0,230 \times 0,315 \times 0,613 \times 0,160)+\mathrm{e} \\
& =0.00711 \text { atau sebesar } 0.71 \%
\end{aligned}
$$

c. Total pengaruh langsung dan tidak langsung

$$
\begin{aligned}
& =0.82 \%+0.71 \% \\
& =1.53 \%
\end{aligned}
$$

Berdasarkan struktur persamaan regresi di atas maka dapat disusun pengaruh langsung komitmen kerja terhadap kinerja dan pengaruh tidak langsung komitmen kerja melalui kepuasan kerja terhadap kinerja karyawan sebagai berikut : 


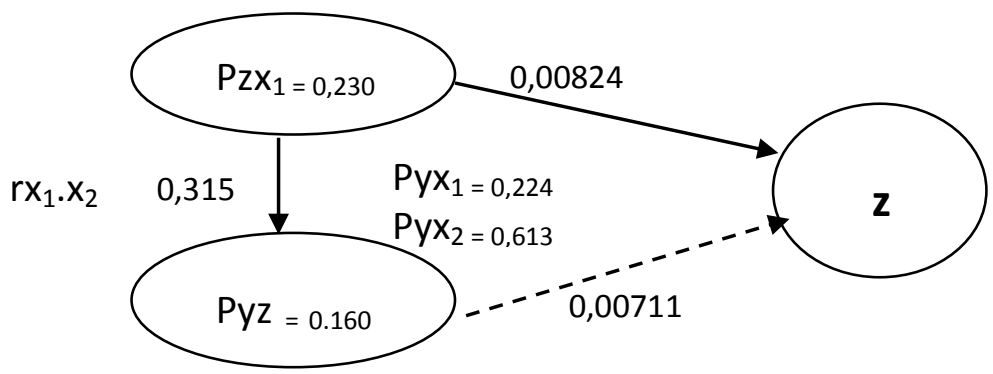

\section{Gambar 5. Pengaruh Komitmen kerja terhadap Kinerja melalui kepuasan Kerja}

Berdasarkan persamaan struktur regresi di atas dapat diterjemahkan bahwa pengaruh langsung komitmen kerja terhadap kinerja karyawan Indofood CBP Sukses Makmur Cabang Jambi melalui kepuasan kerja adalah sebesar 0,00824 atau sebesar 0,82\%, namun demikian pengaruh tidak langsung komitmen kerja melalui kepuasan kerja terhadap kinerja karyawan lebih kecil yaitu sebesar 0,00711 atau sebesar $0,71 \%$, sehingga pengaruh total adalah $0,82+0,71=1,53 \%$.

Dengan nilai $\mathrm{t}$ hitung sebesar 2,565 dan nilai t tabel pada tingkat keyakinan sebesar $96 \%$ atau 0,05 dan nilai $\mathrm{df}=\mathrm{n}-\mathrm{k}$ atau 80-3 $=77$ maka diperoleh nilai $t$ tabel sebesar 1,6660. Hal ini berarti nilai t hitung $(2,565)>$ nilai $t$ tabel $(1,6660)$. Sesuai dengan kaidah pengambilan keputusan maka berarti bahwa komitmen kerja melalui kepuasan kerja secara langsung berpengaruh secara signifikan terhadap kinerja karyawan Indofood CBP Sukses Makmur Cabang Jambi.

8. Pengaruh langsung dan tidak langsung QWL melalui kepuasan kerja terhadap Kinerja

Untuk menjawab tujuan ke sepuluh yaitu mengenai hubungan antara motivasi melalui kepuasan kerja secara bersama sama terhadap kinerja dapat dilihat hasil pengujian sebagaimana tergambar pada lampiran 10 diperoleh hasil pengujian sebagai berikut :

a. Pengaruh langsung $\mathrm{X} 2$ terhadap $\mathrm{Z}$ melalui $\mathrm{Y}$

$$
\begin{aligned}
\mathrm{X}_{2} \Omega \mathrm{Y} \rightarrow \mathrm{Z} & =\left(\mathrm{Pzx}_{2} . \mathrm{Pyx}_{2 .} \mathrm{Pzy}\right) \\
& =(0,602 \times 0,602 \times 0,160) \\
& =0,05798 \text { atau sebesar } 5.79 \%
\end{aligned}
$$

b. Pengaruh tidak langsung $\mathrm{X} 2$ terhadap $\mathrm{Z}$ melalui $\mathrm{Y}$

$$
\begin{aligned}
\mathrm{X}_{2} \Omega \mathrm{Y} \rightarrow \mathrm{Z} & =\left(\mathrm{Pzx}_{2} \cdot \mathrm{Pyx}_{2 .} \mathrm{rx}_{1} \mathrm{x}_{2} \cdot \mathrm{Pyx}_{1} . \mathrm{Pzy}\right) \\
& =(0,602 \times 0.613 \mathrm{x} 0,315 \times 0,224 \times 0,160)+\mathrm{e} \\
& =0.00416 \text { atau sebesar } 0.41 \%
\end{aligned}
$$

c. Total pengaruh langsung dan tidak langsung

$$
=5.79 \%+0.41 \%=6.2 \%
$$

Maka pengaruh langsung komitmen kerja terhadap kinerja dan pengaruh tidak langsung komitmen kerja melalui kepuasan kerja terhadap kinerja karyawan sebagai berikut : 


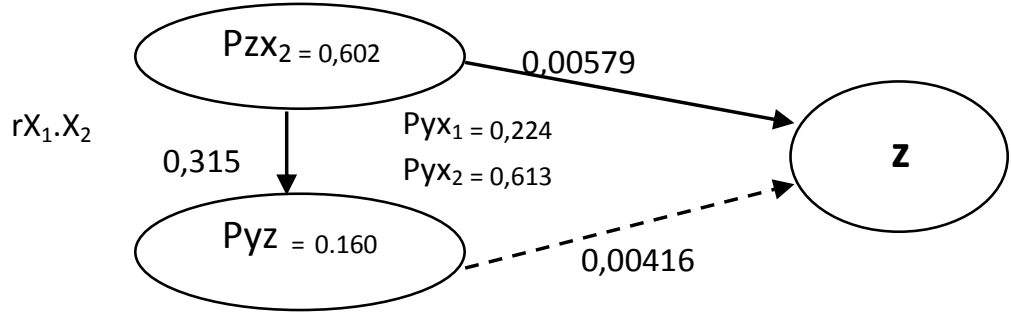

Gambar 4.12. Pengaruh QWL terhadap Kinerja melalui kepuasan Kerja

Berdasarkan persamaan struktur regresi di atas dapat diterjemahkan bahwa pengaruh QWL terhadap kinerja karyawan Indofood CBP Sukses Makmur Cabang Jambi melalui kepuasan kerja adalah sebesar 0,05798 atau sebesar 5,79\%, namun demikian pengaruh tidak langsung QWL melalui kepuasan kerja terhadap kinerja karyawan lebih kecil yaitu sebesar 0,00416 atau sebesar $0,41 \%$, sehingga pengaruh total adalah $6,2 \%$.

Dengan nilai $\mathrm{t}$ hitung sebesar 7,052 dan nilai $\mathrm{t}$ tabel pada tingkat keyakinan sebesar $96 \%$ atau 0,05 dan nilai $\mathrm{df}=\mathrm{n}-\mathrm{k}$ atau 80-3 $=77$ maka diperoleh nilai t tabel sebesar 1,6660. Hal ini berarti nilai t hitung $(3,276)>$ dari nilai $t$ tabel $(1,6660)$. Sesuai dengan kaidah pengambilan keputusan maka berarti bahwa QWL melalui kepuasan kerja secara langsung berpengaruh secara signifikan terhadap kinerja karyawan Indofood CBP Sukses Makmur Cabang Jambi.

Hasil penelitian ini sejalan dengan penelitian yang dilakukan oleh May dan Lau (1999) dimana menunjukkan bahwa kualitas kehidupan kerja mempunyai pengaruh positif dan signifikan terhadap kinerja perusahaan . Adanya kualitas kehidupan kerja juga menumbuhkan keinginan para karyawan untuk tetap tinggal dalam organisasi

\section{Pengaruh Kepuasan kerja Kerja secara parsial terhadap Kinerja}

Untuk menjawab hasil hipotesis ke sebelas mengenai hubungan kepuasan kerja terhadap kinerja karyawan. Berdasarkan tabel 4.32 maka persamaan struktural pengaruh komitmen kerja terhadap kepuasan kerja adalah sebagai berikut

$$
\mathrm{Y} \rightarrow \mathrm{Z}=\text { (Pzy. Pzy) (Pengaruh Langsung) }
$$

Berdasarkan struktur persamaan regresi di atas maka dapat disusun pengaruh langsung pengaruh kepuasan kerja terhadap kinerja karyawan sebagai berikut :

$$
\begin{aligned}
\mathrm{Z} & =0,160 \times 0,160 \mathrm{Y} \\
& =0,0256 \text { atau sebesar } 2.56 \%
\end{aligned}
$$

Berdasarkan persamaan struktur regresi di atas dapat diterjemahkan bahwa pengaruh kepuasan kerja terhadap kinerja karyawan Indofood CBP Sukses Makmur Cabang Jambi adalah sebesar 0,0256 atau sebesar 2,56\%. Dengan nilai $\mathrm{t}$ hitung sebesar 2,101 dan nilai $\mathrm{t}$ tabel pada tingkat keyakinan sebesar $96 \%$ atau 0,05 dan nilai $\mathrm{df}=\mathrm{n}-\mathrm{k}$ atau $80-3=77$ maka diperoleh nilai $\mathrm{t}$ tabel sebesar 1,6660. Hal ini berarti nilai t hitung $(2,101)$ lebih besar dari nilai $t$ tabel $(1,6660)$. Sesuai dengan kaidah pengambilan keputusan maka berarti bahwa kepuasan kerja secara langsung berpengaruh secara signifikan terhadap kinerja karyawan Indofood CBP Sukses Makmur Cabang Jambi.

Hasil penelitian ini sejalan dengan penelitian yang dilakukan oleh M.M. Petty, Gail W.McGee, Jerry W. Cavender ( 2003 ) "A Meta analysis of the relationship between individual job satisfaction and Individual Performance" 
dimana dalam penelitiannya menyimpulkan bahwa kepuasan kerja berhubungan positif dengan kinerja karyawan. Selain itu hasil penelitian ini juga sejalan dengan penelitian yang dilakukan Noor Arifin (2012) yang menemukan bahwa kepuasan berpengaruh terhadap kinerja karyawan CV. DUTA Senen Jepara karena nilai t- statistik (8.227) lebih besar dari tabel 2,01. Dengan demikian dapat dikatakan bahwa semakin tinggi kepuasan kerja karyawan akan semakin tinggi pula kinerjanya. Temuan ini mendukung penelitian Petty. dkk (1984) dan Cheri Ostroff, (1992:35) serta Gianahis (1997) yang menyatakan bahwa kepuasan berpengaruh pada kinerja.

\section{SIMPULAN DAN SARAN Simpulan}

Berdasarkan hasil penelitian sebagaimana diuraikan pada analisa dan pembahasan maka kesimpulan yang dapat diambil dari penelitian ini adalah :

1. Gambaran komitmen Kerja, Quality of Work Life (QWL), kepuasan kerja dan kinerja karyawan PT. Indofood CBP Sukses Makmur Cabang Jambi adalah sebagai berikut :

a. Komitmen Kerja karyawan masih belum memuaskan atau berada pada tingkatan yang cukup baik. Peningkatan pada dimensi memiliki kepedulian, kerelaan memenuhi kewajiban dan tidak ragu, diperlukan agar mencapai tahap yang sangat baik.

b. Quality of Work Life (QWL) karyawan sudah berjalan baik sebagaimana yang diharapkan karyawan pada tingkatan yang cukup baik, masih belum memuaskan atau sesuai dengan yang diharapkan atau berada pada tingkatan yang cukup memenuhi kebutuhan Hal ini menunjukkan bahwa diperlukan upaya yang lebih untuk meningkatkan QWL karyawan pada tingkatan yang optimal.

c. Kepuasan kerja karyawan masih belum memuaskan atau berada pada tingkatan yang cukup baik. Peningkatan komunikasi dan toleransi dengan rekan kerja masih perlu ditingkatkan upaya optimalisasi agar mencapai kepuasan yang baik.

d. Kinerja karyawan pada tingkatan yang sudah baik, namun belum pada tingkatan yang sangat baik,artinya masih diperlukan upaya optimalisasi pada peningkatan kinerja karyawan,

2. Komitmen dan Quality of Work life (QWL) secara bersama-sama berpengaruh positif dan signifikan terhadap kepuasan kerja karyawan . Besarnya pengaruh langsung komitmen kerja dan QWL secara bersama-sama terhadap kepuasan kerja adalah sebesar $42.5 \%$ dan pengaruh tidak langsung sebesar $13.91 \%$. Hasil uji $\mathrm{F}$ hitung sebesar 6.632 dimana $\mathrm{F}$ tabel sebesar 4.28. hal ini berarti bahwa F hitung > F tabel.

3. Pengaruh komitmen kerja secara parsial terhadap kepuasan kerja karyawan adalah positif dan signifikan. Dibuktikan dengan nilai t hitung yaitu sebesar 2.553 dimana nilai $t$ tabel hanya sebesar 1,6660. Pengaruh langsung komitmen kerja terhadap kepuasan kerja sebesar $5.01 \%$. Sedangkan pengaruh tidak langsung komitmen kerja melalui QWL terhadap kepuasan kerja sebesar 4,32\%. Dengan demikian maka pengaruh total komitmen kerja terhadap kepuasan kerja adalah sebesar 9,33\%. Hal ini menunjukkan bahwa dengan tambahan dari variabel QWL maka komitmen kerja dapat meningkatkan kepuasan kerja menjadi 9,33\%. 
4. Pengaruh langsung Quality of Work life (QWL) terhadap kepuasan kerja karyawan adalah positif dan signifikan. Dengan nilai t hitung sebesar 6.994 lebih besar dari nilai $\mathrm{t}$ tabel 1.6660. Pengaruh Langsung QWL terhadap kepuasan kerja karyawan sebesar 37,57 \%. Sedangkan pengaruh tidak langsung QWL melalui komitmen kerja terhadap kepuasan kerja sebesar 4,32 \%. Berarti bahwa untuk meningkatkan kepuasan kerja dapat dilakukan dengan meningkatkan QWL karyawan, sementara apabila dilakukan kebijakan peningkatan komitmen kerja karyawan akan memberikan dampak tidak langsung yang terhadap peningkatan kepuasan kerja karyawan.

5. Komitmen dan Quality of Work life (QWL) mampu secara bersama-sama berpengaruh positif dan signifikan terhadap kinerja karyawan. Hasil pengujian pengaruh langsung adalah sebesar $53.62 \%$ serta pengaruh tidak langsung komitmen kerja dan QWL terhadap kinerja sebesar $16.88 \%$, sementara nilai $F$ hitung 62.554 lebih besar dari nilai $F$ tabel 3.15. Jika hasil analisis statistik dan deskriptif ini dihubungkan dengan analisis verifikatif maka, nampak jelas bahwa semakin banyak karyawan yang melakukan upaya-upaya kearah peningkatan komitmen kerja dan QWL, tentunya akan sangat berpengaruh pada peningkatan kinerja Indofood CBP Sukses Makmur Cabang Jambi secara keseluruhan.

6. Pengaruh komitmen kerja secara parsial terhadap kinerja karyawan adalah positif dan signifikan. Pengaruh langsung komitmen kerja terhadap kinerja sebesar 2,6 \%, namun demikian pengaruh tidak langsung komitmen kerja melalui kepuasan kerja terhadap kinerja karyawan lebih besar yaitu sebesar $3,66 \%$. Dengan nilai t hitung sebesar 3,276 > dari nilai t tabel 1,6660.

7. Pengaruh QWL terhadap kinerja karyawan secara parsial adalah positif dan signifikan. Hasil pengujian bahwa pengaruh langsung QWL terhadap kinerja karyawan sebesar 50,97\%, namun demikian pengaruh tidak langsung QWL melalui kepuasan kerja terhadap kinerja adalah sebesar 3,66 \%. Dengan nilai t hitung sebesar 6,967 > nilai t tabel sebesar 1,6660.

8. Pengaruh komitmen kerja dan QWL secara bersama-sama melalui kepuasan kerja terhadap kinerja adalah positif. Pengaruh langsung komitmen kerja dan QWL terhadap kinerja melalui kepuasan kerja sebesar $6.72 \%$, sementara pengaruh tidak langsung sebesar $0.57 \%$.. Dengan nilai $\mathrm{F}$ hitung 45,301 lebih besar dari nilai $\mathrm{F}$ tabel 3,18, maka terdapat pengaruh linear yang sangat kuat antara variabel komitmen kerja dan QWL serta kepuasan kerja terhadap kinerja karyawan.

9. Pengaruh komitmen kerja melalui kepuasan kerja terhadap kinerja karyawan adalah positif dan signifikan. Dengan nilai thitung 3,276>dari nilai t tabel 1,6660. Hasil pengujian yang dilakukan terdapat pengaruh langsung komitmen kerja terhadap kinerja karyawan melalui kepuasan kerja sebesar $0,82 \%$, namun demikian pengaruh tidak langsung komitmen kerja melalui kepuasan kerja terhadap kinerja karyawan lebih kecil yaitu sebesar 0,71\%. Melalui kepuasan kerja karyawan maka diharapkan akan mendorong peningkatan komitmen kerja karyawan. Kepuasan kerja memberikan dorongan yang kuat untuk meningkatkan komitmen kerja karyawan . Melalui dorongan yang diberikan komitmen kerja maka akan terjadi peningkatan kepuasan kerja yang pada gilirannya akan memberikan dampak terhadap peningkatan kinerja karyawan secara keseluruhan. 
10. Pengaruh QWL melalui kepuasan kerja terhadap kinerja karyawan adalah Signifikan. Hasil perhitungan pengaruh langsung QWL terhadap kinerja karyawan melalui kepuasan kerja sebesar 5,79\% dan pengaruh tidak langsung QWL melalui kepuasan kerja terhadap kinerja karyawan lebih kecil yaitu sebesar 0,00416 atau sebesar $0,41 \%$. Dengan nilai t hitung 7,052 lebih besar dari nilai $\mathrm{t}$ tabel 1,6660. Hasil penelitian ini menunjukkan bahwa pengaruh tidak langsung antara QWL melalui kepuasan kerja terhadap kinerja ternyata belum begitu besar. Hal ini menunjukkan bahwa kepuasan kerja belum memberikan sumbangan yang besar ikut membantu QWL dalam meningkatkan kinerja karyawan PT. Indofood CBP Sukses Makmur Cabang Jambi.

11. Pengaruh kepuasan kerja terhadap kinerja karyawan adalah sebesar 0,256 atau sebesar 2.56 persen. Dengan nilai t hitung $(2,101)$ lebih besar dari nilai t tabel $(1,6660)$ berarti bahwa kepuasan kerja secara langsung berpengaruh secara signifikan terhadap kinerja karyawan. Dengan demikian dapat dikatakan bahwa semakin tinggi kepuasan kerja karyawan akan semakin tinggi pula kinerjanya.

\section{Saran}

Adapun secara operasional dapat diberikan saran kepada Pimpinan PT. Indofood CBP Sukses Makmur Cabang Jambi dan seluruh jajarannya sebagai berikut :

1. Agar lebih mengoptimalkan kualitas kerja dengan cara tetap melakukan kajian hasil kerja yang sesuai dengan standar kerja yang secara baku telah ditetapkan, termasuk melibatkan pihak-pihak independent dalam menilai kualitas kerja karyawan .

2. Untuk menunjang peningkatan hasil kerja hendaknya secara berkala mendorong peningkatan pengetahuan karyawan melalui berbagai pendidikan dan pelatihan baik secara formal maupun non formal.

3. Untuk menunjang aktivitas kerja agar lebih terampil dan memiliki nilai yang positif maka perlu mendorong peningkatan kapasitas dan kapabilitas karyawan agar tetap memiliki kehandalan dalam bekerja. Hal in dilakukan melalui berbagai training dan stimulus dan penyerahan kewenangan.

4. Diharapkan memberikan kebebasan brekreasi dalam koridor peningkatan komitmen dan menciptakan suasana kerja yang harmonis, memelihara suasana kerja yang kondusif, dinamis dan dalam suasana penuh kekeluargaan. Mendorong karyawan untuk memliki sikap kerja yang positif dan mendorong setiap karyawan untuk memliki kemampuan serta kecakapan dalam bekerjasama.

5. Diharapkan mampu meningkatkan komitmen melalui pendidikan dan pelatihan, baik fungsional, teknis maupun struktural agar secara berkala dan berkelanjutan dapat diperoleh profil karyawan yang memiliki komitmen yang terus berkembang.

6. Diharapkan mampu secara konsisten dan penuh tanggungjawab untuk meningkatkan QWL karyawan melalui berbagai kebijakan baik punishment maupun reward.

DAFTAR PUSTAKA

Allen, Natalie J., and John P. Meyer, 1990, The Measurement and Antecedent of Affective, Continuance and Normative Commitment to the Organization, Journal of Occupational Psychology. 
Arifin, Noor., 1999, Aplikasi Konsep Quality of Work Life dalam Upaya Menumbuhkan Motivasi Karyawan Berkinerja Unggul, Usahawan.Jakarta.

As'ad, Mohamad.,1991, Kepemimpinan Efektif dalam Perusahaan, Suatu Pendekatan Psikologik, Edisi Kedua, Liberty, Yogyakarta.

Anwar Prabu Mangkuegara, DR., Msi., 2006, Evaluasi Kinerja SDM, Edisi Kedua, Refika Aditama, Bandung.

Bernardin, H. John dan Russel, J.E.A., 1993, Humans Resource Management : an Experimental Approach, International Edition, Singapore, McGraw Hill. Inc.

Bernardin \& Russel, 2002, Performing In Organization, terjemahan Erlangga, Jakarta.

Sri Budi Cantika, 2005, Manajemen Sumber Daya Manusia, UMM Press, Malang. Cascio, W.F., 2006, Applied Psychology in Personal Management, 4th Edition, Prentice Hall International Inc.

Cheri Ostroff, 1992, The Relatinonship Between Satisfaction, Attitudes and Performance, an Organizational Level Analysis, Journal of Applied Psychology.

Dessler, Gary. 2001, Human Resourrce Management. Terjemahan Benyamin Molan, Jakarta: PT. Prehalindo.

Elmuti, Dean, 2003, Impact of Internet Adided Self-Management Teams on Quality of Work-Life and Performance, Journal of Business Strategies.

Fields, Mitchel W., and James W. Thacker, 1992, Influence of Quality of Work Life on Company and Union Commitment, Academy of Management Journal.

Gomes, Louis, 2002, Managing Human Resources. New Jersey: Prentice Hall International,Inc.

Hasibuan Malayu SP, 2000, Manajemen Sumber Daya Manusia Dasar dan Kunci Keberhasilan, Armanco Bandung.

Handoko, T.Hani, 2004, Manajemen Sumber Daya Manusia, BP- FE UGM, Yogyakarta.

Hendri Simamora, 2002, Manajemen Sumber Daya Manusia, STIE YKPN, Jakarta.

Luthans, F., 1998, Organizational Behaviour, 8th edition, McGraw Hill

Nawawi, Hajari H., 1997, Manajemen Sumber Daya Manusia untuk Bisnis yang Kompetitif, Gajah Mada Univercity Press, Yogyakarta.

Naraha, Talizuhu. 2001, Manajemen Kinerja, LPFE-UI, Jakarta

Petty, M.M., Gail W. McGee, Jerry W. Cavender, 1984, A Meta-Analysis of the Relationship Between Individual Job Satisfaction and Individual Performance, Academy of Management Review.

Pruijt, Hans, 2003,Performance and Quality of Work Life, Journal of Organizational Change Management.

Russel, Bernardin, 2003, Mengukir Prestasi : Panduan Menjadi Profesional. Misaka Galiza, Jakarta:

Robbins, S.P, 2003, Organizational Behavior, terjemahan Tanty S. Tarigan), Prehallindo, Jakarta.

Siagian P. Sondang, 1995, Teori Pengembangan Organisasi, Jakarta, Bumi Aksara, Sinar Grafika Offset. 
Sedarmayanti, 2000, Restrukturisasi dan Pemberdayaan Organisasi Untuk MenghadapDinamika Perubahan Lingkungan, Mandar Maju, Bandung

Sedarmayanti, 2001, Manajemen Sumber Daya Manusia, Mandar Maju, Bandung

Sedarmayanti, 2004, Manajemen Kepegawaian, Mandar Maju, Bandung

Sulistiyani, Ambar Teguh dan Rosidah, 2003, Manajemen Sumberdaya Manusia, Yogyakarta, Graha Ilmu, 2003

Wyatt, Thomas., and Chay Yue Wah, 2001, Perception of QWL : a Study ofSingaporean Employees Development, Management Memo

Zin, Razali Mat, 2004, Perception of Professional Engineers Toward Quality of Work Life and Organizational Commitment, Gajahmada International Journal of Business. 